\title{
Clinical and Biochemical Observations in Two Cases of Hartnup Disease
}

\author{
PAUL W. K. WONG and P. M. PILLAI \\ From the Mental Retardation Research Unit and the University Unit, Royal Manchester Children's Hospital
}

Hartnup disease, first described by Baron, Dent, Harris, Hart, and Jepson (1956), is characterized by a photosensitive pellagra-like rash, cerebellar ataxia, generalized renal aminoaciduria, hyperindoluria, and hypertryptophanuria. Nemeth and Nachmias (1958) suggested that in this disorder there might be a deficiency of tryptophan pyrrolase, the enzyme that catalyses tryptophan to formylkynurenine. Milne, Crawford, Girão, and Loughridge (1960) produced evidence that there was an impairment of tryptophan absorption in the intestine in addition to that observed in the renal tubules. The abnormally high urinary output of indolic metabolites was demonstrated by Asatoor, Craske, London, and Milne (1963) to be the result of normal bacterial action on the unabsorbed tryptophan in the intestine and not the result of an abnormal intestinal flora. de Laey, Hooft, Timmermans, and Snoeck (1964) using intravenous tryptophan loading tests, were able to show that intravenously administered tryptophan was metabolized by a Hartnup patient in a similar manner to the control. The evidence accumulated to date suggests that the primary abnormality in Hartnup disease is a defective transport of tryptophan, and probably other neutral amino acids, in the small intestine and renal tubules. A total of 19 cases has been reported since the original description (Baron et al., 1956; Jonxis, 1957; Henderson, 1958; Weyers and Bickel, 1958; Hersov and Rodnight, 1960; Albers and Wadman, 1961; Hooft, De Laey, Timmermans, and Snoeck, 1962; Halvorsen and Halvorsen, 1963; Srikantia, Venkatachalam, and Reddy, 1964; Visakorpi, Hjilt, Lahikainen, and Öhman, 1964).

The present paper describes 2 new cases from unrelated families and biochemical studies which confirm and elaborate on previous observations.

Received November 11, 1965.

\section{Case Reports}

Case 1. A boy, aged 4.1 years, was referred to the Royal Manchester Children's Hospital because of episodes of unconsciousness. After an uneventful pregnancy he was delivered normally at term; his birth weight was $2 \cdot 1 \mathrm{~kg}$. His development was normal until he was 18 months old when he started to suffer from bouts of vomiting. Between the ages of 2 and 3 years he had 8 episodes of unconsciousness which lasted for varying times: on one occasion there was impaired consciousness for 7 hours. Some of the attacks were heralded by vomiting in the morning and then he would become limp and pale with rolling of the eyes. He would partially recover and this situation would be repeated several times in the day. For the 6 months before admission, multiple skin lesions appeared on the exposed parts of the body at irregular intervals. The rash consisted of macular and papular and occasional purpuric lesions. Some were vesicular and varied in size from 0.5 to $3.0 \mathrm{~cm}$. in diameter. Both his parents, who are not related, and his sister, are normal, and there has been no similar illness in any other relative.

The physical examination was normal on several occasions; there was no neurological abnormality. At the age of 4 years 10 months his weight was below the third percentile, and his height was below the tenth percentile. His IQ was 96 (Stanford Binet).

Routine laboratory studies showed a haemoglobin of $73 \%$, WBC $9,500 /$ c.mm., with a normal differential count. Fasting blood glucose and glucose tolerance test were normal. Radiological examinations of the skull and the abdomen were normal. There was no evidence of renal calcification. The electroencephalogram showed a slight generalized dysrhythmia but no focal features or epileptic discharges. Repeated urine examinations showed no sugar or protein, but a persistent and marked generalized aminoaciduria was noted. Two-dimensional paper chromatography revealed strong spots of glycine, serine, histidine, glutamine, leucine, valine, threonine, tyrosine, alanine, asparagine, and aspartic acid. Amino- $\mathrm{N}$-butyric acid, tryptophan, and $\beta$-aminoisobutyric acid were also identified. On some occasions ornithine, citrulline, and phenylalanine were also found, but there was never any proline or hydroxyproline. Serum albumin was $4.0 \mathrm{~g} . / 100 \mathrm{ml}$; ; globulin $3 \cdot 1 \mathrm{~g} . / 100$ ml.; alkaline phosphatase 23 King Armstrong Units $/ 100$ $\mathrm{ml}$. Serum electrolytes and liver function tests were 
normal. The blood urea $26 \mathrm{mg} . / 100 \mathrm{ml}$; calcium $9 \cdot 8$ mg./100 ml.; phosphorus $4.0 \mathrm{mg} . / 100 \mathrm{ml}$; fasting ammonia $92 \mu \mathrm{g} . / 100 \mathrm{ml}$. Plasma amino acids, determined by ion exchange chromatography, were normal or low.

Case 2. A 7-month-old boy was admitted because of an upper respiratory infection. Following a normal pregnancy he was delivered uneventfully at term. His birth weight was $2 \cdot 7 \mathrm{~kg}$. The developmental history suggested some retardation; he smiled at 10 weeks of age, held his head steady at 5 months, but did not reach for objects though he was interested in them; he could sit only with support. At the age of 7 months, his weight was below the third percentile and his length was at the third percentile. There was no history of skin rash or sensitivity to sunlight and no previous illnesses. He was an odd-looking boy with a prominent forehead. Repeated exposure to direct sunlight failed to produce any rash. His parents, who are unrelated, and his sister are normal.

Laboratory studies showed the following results: haemoglobin $70 \%$, WBC 12,000/c.mm., with normal differential count. There was no proteinuria or glycosuria. Two-dimensional paper chromatography of urine showed a generalized aminoaciduria with strong spots of glycine, serine, glutamine, alanine, threonine, leucine, and valine. Asparagine, tyrosine, histidine, lysine, citrulline, and tryptophan were moderately strong. Taurine, $\beta$-amino-isobutyric acid, phenylalanine, and cysteic acid were also seen. Proline and hydroxyproline were absent.* Serum albumin was 4.0 g. $/ 100 \mathrm{ml}$., globulin 2.5 g. $/ 100 \mathrm{ml}$., with a normal pattern on paper electrophoresis. Plasma alkaline phosphatase was 27 King Armstrong units $/ 100 \mathrm{ml}$. Serum calcium $10.0 \mathrm{mg} . / 100 \mathrm{ml}$., inorganic phosphorus $5.6 \mathrm{mg} . / 100 \mathrm{ml}$. Fasting blood glucose and glucose tolerance tests were normal; serum electrolytes, blood urea, and liver function tests were also normal. Plasma amino acids were normal or low. He was chromatin negative and his chromosomes were of normal male karyotype. His electroencephalogram was normal.

\section{Materials and Methods}

Oral and intravenous L-tryptophan loading tests were performed in the patients and controls. Three days before and during the loading tests, the children were given a constant protein diet, free of banana, tomato, and nuts. Oral tryptophan was administered in a solution of orange squash; intravenously administered tryptophan was prepared according to the method of Drummond, Michael, Ulstrom, and Good (1964) and was infused evenly over a period of 4 hours. $100 \mathrm{mg}$. L-tryptophan per kg. body weight was used both for the oral and the intravenous loading. Blood was taken into heparinized tubes for plasma tryptophan estimation by the method of Duggan and Udenfriend (1956). Urine was collected under ice without preservative in consecutive periods of 4 hours, for 4 hours before and 24 hours after the loading.

* This chromatogram and the one from Case 1 were considered to be typical of Hartnup disease, and this was confirmed by Dr. Roland Westall of University College Hospital, London.
All samples were immediately frozen after collection and estimations were made of indoxyl sulphate by a modification of the method of Sharlit (1933); kynurenine by a modification of the method of Coppini, Benassi, and Monotorsi (1959); indole-3-acetic acid by the method of Weissbach, King, Sjoerdsma, and Udenfriend (1959); 5-hydroxyindoleacetic acid by the method of Udenfriend, Titus, and Weissbach (1955), and urine tryptophan by paper chromatography using a solvent of butanol-acetic acid-water (12:3:5) and staining with Ehrlich solution. Estimation of stool tryptophan was carried out according to the method of Drummond et al. (1964).

For the study of parents and sibs, only oral loading tests were performed. The subjects were fasted throughout the period of the experiment, and blood was taken for tryptophan estimation at 0,2 , and 4 hours after loading.

\section{Results}

Fig. 1 and 2 show the plasma levels of tryptophan after oral and intravenous loading, respectively. In the controls, a rapid increase in plasma tryptophan

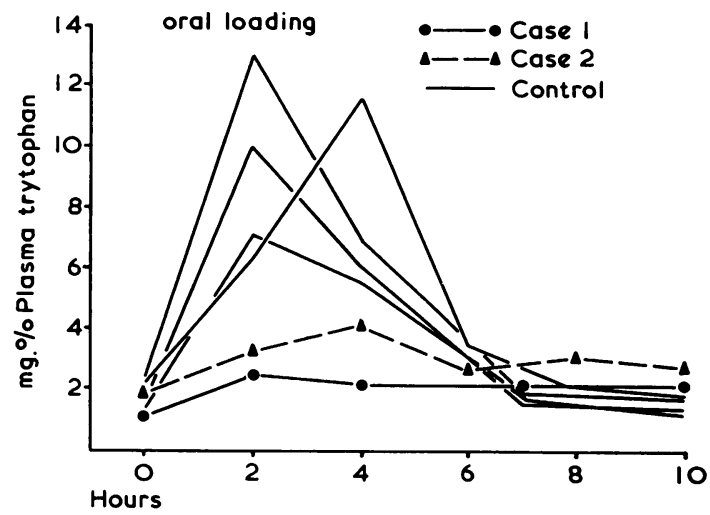

Fig. 1.-Plasma tryptophan levels after oral loading.

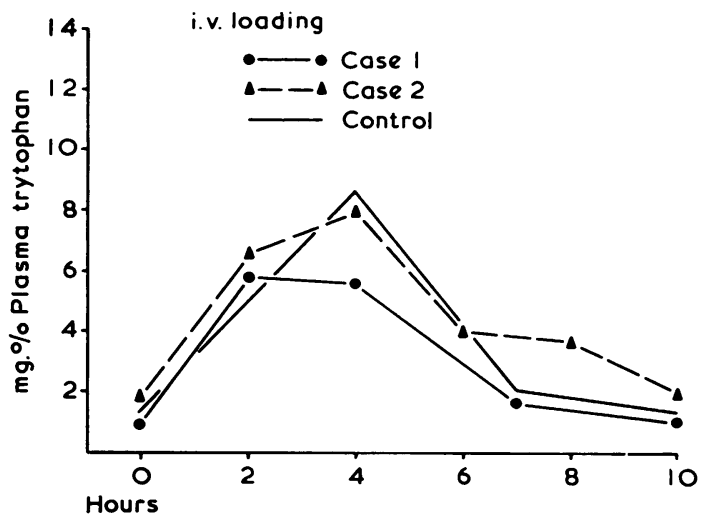

FIG. 2.-Plasma tryptophan levels after intravenous loading. 


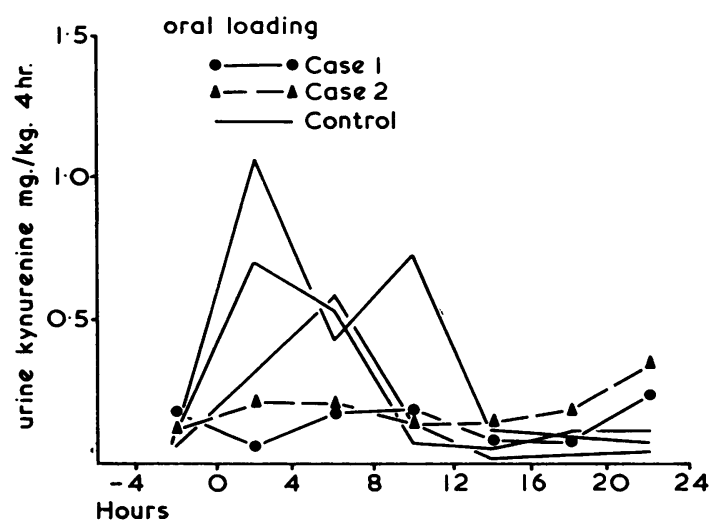

FIG. 3.-Urinary excretion of kynurenine after oral loading.

after oral loading was observed, reaching a maximum usually at 2 hours. However, in the patients there was only a small, but prolonged, rise of plasma tryptophan after oral loading. The increase in plasma tryptophan after intravenous loading was identical in the patients and one control, and was similar to the increase after oral loading in the controls.

Fig. 3 and 4 show the urinary excretion of kynurenine. In the controls, oral tryptophan loading resulted in a ten- to twentyfold increase in kynurenine excretion, which occurred within the first 8 to 12 hours. In the patients, oral loading failed to produce significant increase of kynurenine excretion. However, after intravenous loading the increase of kynurenine excretion was the same in the patients and the controls.

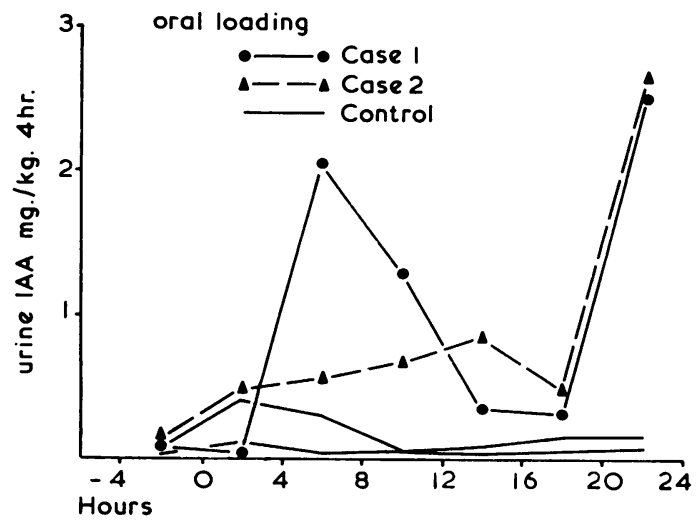

FIG. 5.-Urinary excretion of indole-3-acetic acid after oral loading.

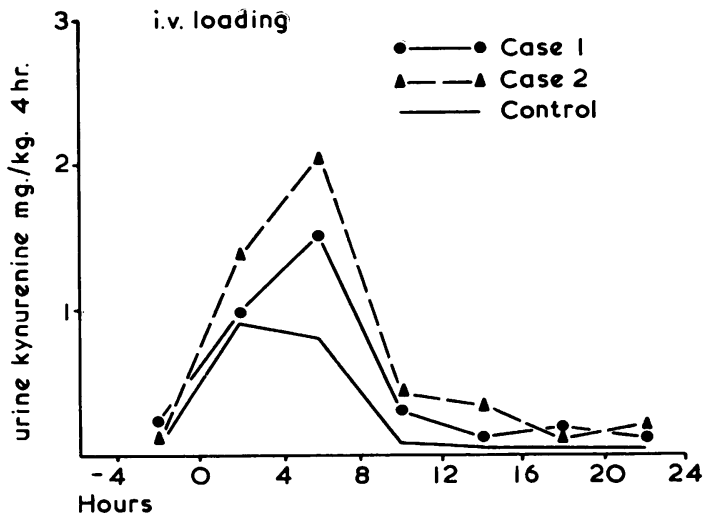

FIG. 4.-Urinary excretion of kynurenine after intravenous loading.

Fig. 5 and 6 show the excretion of indole-3-acetic acid; and Fig. 7 and 8 show the excretion of indoxyl sulphate. It is seen that after oral loading the total 24-hour excretion of indole-3-acetic acid was 5 to 10 times higher in the patients than in the controls. Further, there was a marked increase between 20 and 24 hours, which did not occur after intravenous loading. Similarly, after oral loading, the total 24-hour excretion of indoxyl sulphate was higher in the patients than in the controls. There was also a marked rise between 20 and 24 hours; this delayed increase was less obvious after intravenous loading. In this context it should be remembered that, following the intravenous or oral load, the patient was allowed the usual meals at normal times.

Table I shows the urinary excretion of 5-hydroxyindoleacetic acid after tryptophan loading in Case 1

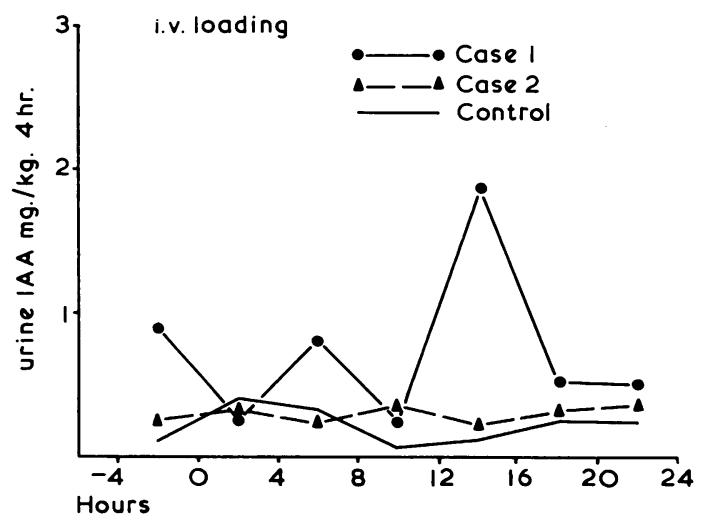

FIG. 6.-Urinary excretion of indole-3-acetic acid after intravenous loading. 


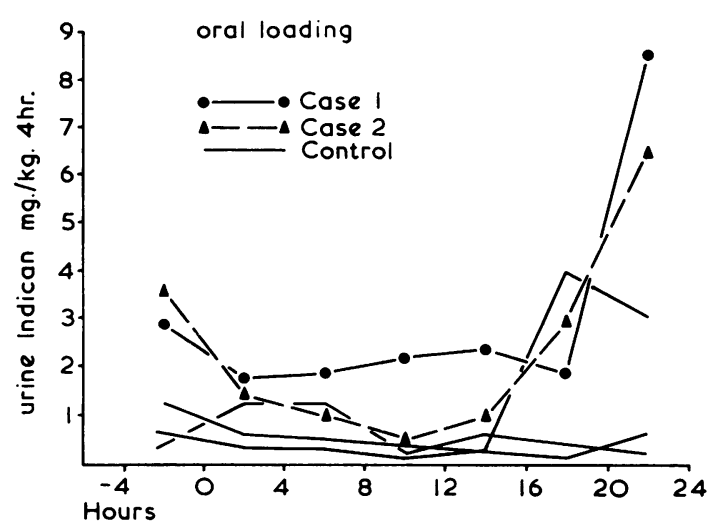

FIG. 7.-Urinary excretion of indoxyl sulphate after oral loading.

and control; the patient excreted about $30 \%$ less 5-hydroxyindoleacetic acid than the control over 24 hours. However, there was no significant difference between oral and intravenous loading.

TABLE I

Urinary Excretion of 5-hydroxyindoleacetic Acid ( $\mu$ g./kg. 4 hours)

\begin{tabular}{c|c|c|c|c}
\hline \multirow{2}{*}{ Hours } & \multicolumn{2}{|c|}{ Oral Loading } & \multicolumn{2}{c}{ Intravenous Loading } \\
\cline { 2 - 3 } & Case 1 & Control & Case 1 & Control \\
\hline-4 to 0 & $74 \cdot 0$ & $16 \cdot 4$ & $23 \cdot 6$ & $84 \cdot 0$ \\
0 to 4 & $28 \cdot 8$ & $53 \cdot 3$ & $22 \cdot 5$ & $97 \cdot 0$ \\
4 to 8 & $30 \cdot 5$ & $81 \cdot 6$ & $46 \cdot 2$ & $46 \cdot 0$ \\
8 to 12 & $17 \cdot 0$ & $23 \cdot 0$ & $14 \cdot 5$ & $36 \cdot 0$ \\
12 to 16 & $9 \cdot 6$ & $31 \cdot 0$ & $7 \cdot 0$ & $43 \cdot 0$ \\
16 to 20 & $10 \cdot 9$ & $116 \cdot 0$ & $18 \cdot 6$ & $26 \cdot 0$ \\
20 to 24 & $49 \cdot 0$ & $3 \cdot 5$ & $29 \cdot 1$ & $43 \cdot 0$ \\
\hline
\end{tabular}

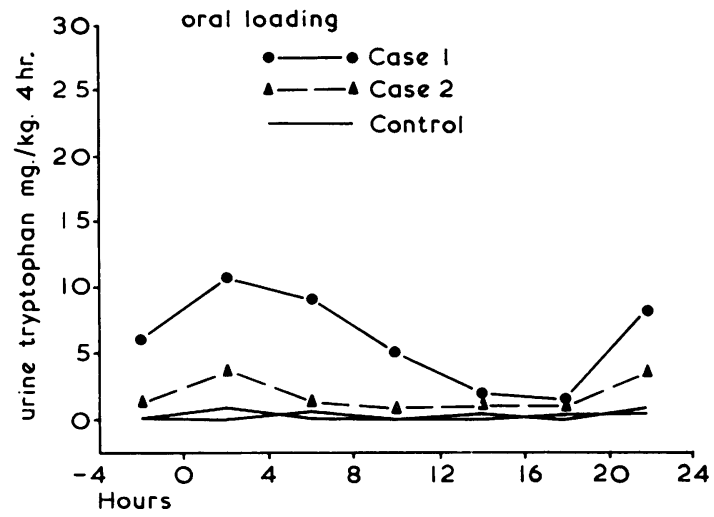

FIG. 9.-Urinary excretion of tryptophan after oral loading.

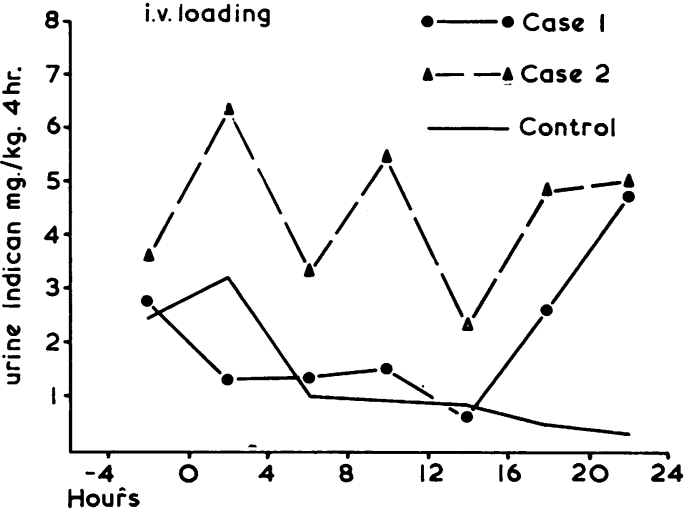

FIG. 8.-Urinary excretion of indoxyl sulphate after intravenous loading.

Fig. 9 and 10 show the excretion of tryptophan in the urine. While tryptophan excretion in the controls was minimal after oral loading, both patients had marked tryptophanuria, and after intravenous loading this was even more marked, particularly in Case 1.

In the controls without tryptophan loading and after both oral and intravenous loading, total 24hour stool specimens contained little or no tryptophan, suggesting that absorption was complete or almost complete. In the patients without tryptophan loading and after intravenous loading, 24-hour stool specimens contained 15 to $19 \mathrm{mg}$. of tryptophan. On the other hand, after oral loading, the patients excreted 3 to 5 times more tryptophan in their stools.

The mean and standard deviation of plasma tryptophan after oral loading in the parents and

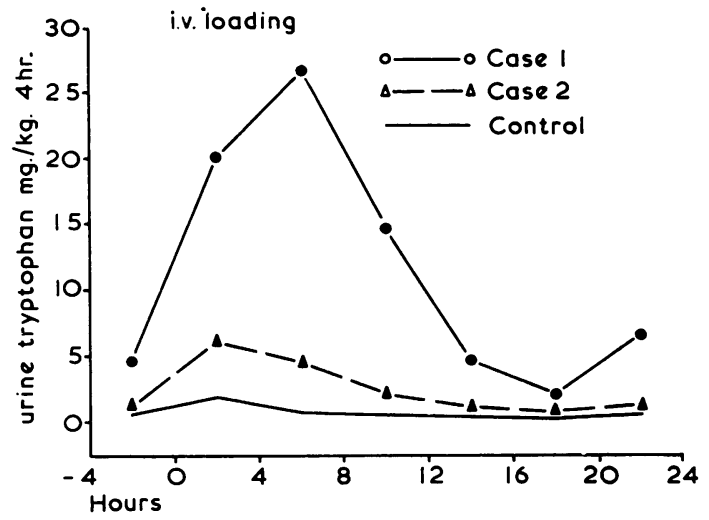

FIG. 10.-Urinary excretion of tryptophan after intravenous loading. 
TABLE II

Plasma Tryptophan (mg./100 ml.) after Oral Loading

\begin{tabular}{|c|c|c|c|c|c|c|}
\hline & & & No. & 0 Hour Mean $\pm S D$ & 2 Hour Mean $\pm S D$ & 4 Hour Mean $\pm S D$ \\
\hline $\begin{array}{l}\text { Controls } \\
\text { Parents } \\
\text { Probability : }\end{array}$ & $\begin{array}{l}\cdots \\
\cdots\end{array}$ & $\begin{array}{ll}\cdots & \ldots \\
\cdots & \cdots \\
\cdots & \end{array}$ & $\begin{array}{l}8 \\
3 \star\end{array}$ & $\begin{array}{c}1 \cdot 44 \pm 0 \cdot 220 \\
1 \cdot 23 \pm 0 \cdot 125 \\
\text { N.S. }\end{array}$ & $\begin{array}{c}13 \cdot 74 \pm 2 \cdot 08 \\
8 \cdot 97 \pm 2 \cdot 02 \\
0.01\end{array}$ & $\begin{array}{c}10 \cdot 37 \pm 2 \cdot 26 \\
7 \cdot 33 \pm 1 \cdot 91 \\
\text { N.S. }\end{array}$ \\
\hline
\end{tabular}

$\star$ The father of Case 1 was not available for study.

adult controls are shown in Table II. While all the controls had a peak level at 2 hours, both the mothers of the patients had a higher plasma tryptophan level at 4 hours than at 2 hours. The lower plasma tryptophan levels attained 2 hours after oral loading in the parents are statistically significant $(p=0.01)$.

After oral tryptophan loading, the sister of Case 1 showed a normal increase in plasma tryptophan. The sister of Case 2, who was clinically normal, had plasma tryptophan levels of $1.1 \mathrm{mg} ., 4.2 \mathrm{mg}$., and $2.6 \mathrm{mg}$. at 0,2 , and 4 hours, respectively, after oral loading. This suggested that she had some impairment of tryptophan absorption; and it was confirmed onr epeat investigation.

\section{Discussion}

The diagram in Fig. 11 represents the metabolic pathways of L-tryptophan. Milne et al. (1960) postulated that in Hartnup disease there was a defective transport of tryptophan in the intestine as well as in the renal tubules. The following observations in the present study confirm this hypothesis: (1) oral tryptophan loading produced a small but prolonged increase of plasma tryptophan; (2) intravenous tryptophan loading resulted in a normal increase of plasma tryptophan and a more marked tryptophanuria. de Laey et al. (1964), using in vitro studies with intestine and liver homogenate of rats, demonstrated the inhibitory effect of indoxyl sulphate on tryptophan pyrrolase and kynurenine formamidase (formylase). They, therefore, postulated that, 'the high indole formation in the Hartnup patients can inhibit the kynurenine metabolic pathway, by which a cellular nicotinamide deficiency can arise.' The present observation, that Hartnup patients under normal dietary conditions and without antibiotic therapy or vitamin supplement excreted a normal amount of kynurenine after intravenous tryptophan loading, contradicts this hypothesis. That the inhibitory effect of indoxyl sulphate to the kynurenine pathway is unlikely to occur to a significant extent in vivo is further supported by the early increase of kynurenine excretion ( 4 to 8 hours) and the delayed rise of indoxyl sulphate excretion (20 to 24 hours) after tryptophan loading. It appears, therefore, that the deficiency of endogenous nicotinamide is due mainly to a much decreased availability of L-tryptophan, as a result of decreased intestinal absorption and increased renal excretion of this amino acid.

The less marked increase of indole-3-acetic acid and indoxyl sulphate after intravenous loading, as compared with oral loading, is compatible with the

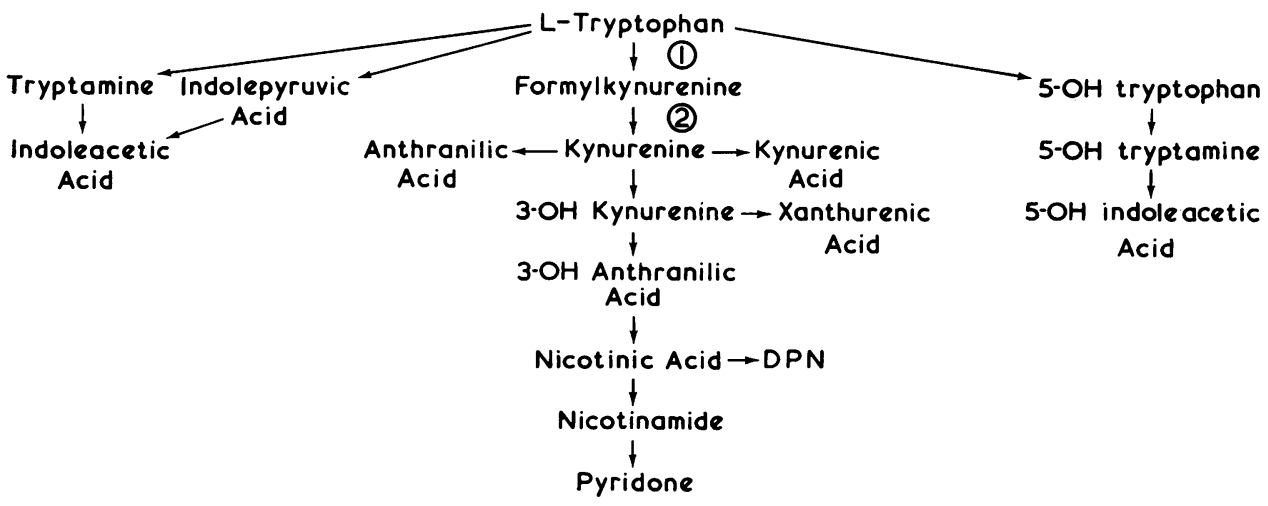

FIG. 11.-Metabolic pathways of L-tryptophan. Reaction (1) is catalysed by tryptophan pyrrolase. Reaction (2) is catalysed by formylase. 
theory that the unabsorbed tryptophan leads to their increased production by the action of intestinal bacteria.

Data from oral tryptophan loading tests of the parents and adult controls suggest that there is a partial defect in tryptophan transport in the intestine of the parents. This lends support to Baron et al.'s postulate (1956) that this disease is inherited through autosomal recessive genes.

Further questions concerning the primary abnormality need to be answered. (1) Is the defective transport of tryptophan a universal abnormality of all cell membranes? (2) Do tyrosine, phenylalanine, leucine, and valine, which were observed to be increased in the stools of the Hartnup patients by Milne et al., share the same defective transport mechanism as tryptophan ? (3) Is there in Hartnup patients an inhibitor of the tryptophan transport mechanism? If so, the inhibitor or the excessive unabsorbed tryptophan may singly or together inhibit the transport of other amino acids.

\section{Summary}

The present paper describes two new cases of Hartnup disease from unrelated families. The characteristic abnormalities of L-tryptophan metabolism after oral loading are observed in both cases and agree with the data of Milne et al. (1960). Intravenously administered tryptophan is normally metabolized. The parents have a significantly lower plasma tryptophan level two hours after oral loading, suggesting that they have a partial defect in tryptophan absorption. This supports the hypothesis that Hartnup disease is an autosomal recessive abnormality. The present observations confirm the theory that a defective transport of tryptophan in the intestine and the renal tubules is the primary abnormality in Hartnup disease.

The authors wish to thank the Research Committee of the Manchester Regional Hospital Board, the Rag Fund of the University of Manchester, the Wellcome Trust, and the Swinton and Pendlebury Branch of the National Society for Mentally Handicapped Children for their financial assistance. They also wish to express their appreciation to Professor Wilfrid Gaisford and Dr. Neil Gordon for their permission to study and to report their cases; and to Dr. G. M. Komrower for his advice and for reviewing the manuscript. The authors are indebted to Miss E. M. Hammond and Mr. M. Hirst for their skilful technical assistance. One of the authors (P.W.K.W.) is supported by a grant from the Children's Research Fund.

\section{REFERENCES}

Albers, F. H., and Wadman, S. K. (1961). Een patiënte met H-ziekte. Maandschr. Kindergeneesk., 29, 102.

Asatoor, A. M., Craske, J., London, D. R., and Milne, M. D. (1963). Indole production in Hartnup disease. Lancet, 1, 126.

Baron, D. N., Dent, C. E., Harris, H., Hart, E. W., and Jepson, J. B. (1956). Hereditary pellagra-like skin rash with temporary cerebellar ataxia, constant renal amino-aciduria, and other bizarre biochemical features. ibid., 2, 421 .

Coppini, D., Benassi, C. A., and Monotorsi, M. (1959). Quantitative determination of tryptophan metabolites (via kynurenine) in biologic fluids. Clin. Chem., $5,391$.

Drummond, K. N., Michael, A. F., Ulstrom, R. A., and Good, R. A (1964). The blue diaper syndrome: familial hypercalcemia with nephrocalcinosis and indicanuria. Amer. F. Med., 37, 928.

Duggan, D. E., and Udenfriend, S. (1956). The spectrophotofluorometric determination of typtophan in plasma and of tryptophan and tyrosine in protein hydrolysates. $\mathcal{F}$. biol. Chem., 223, 313.

Halvorsen, K., and Halvorsen, S. (1963). Hartnup disease. Pediatrics, 31, 29.

Henderson, W. (1958). A case of Hartnup disease. Arch. Dis. Childh., 33, 114.

Hersov, L. A., and Rodnight, R. (1960). Hartnup disease in psychiatric practice: clinical and biochemical features of three cases. F. Neurol. Neurosurg. Psychiat., 23, 40.

Hooft, C., De Laey, P., Timmermans, J., and Snoeck, J. (1962). La maladie de Hartnup. Acta paediat. belg., 16, 281.

Jonxis, J. H. P. (1957). Oligophrenia phenylpyruvica en de Hartnupziekte. Ned. T. Geneesk., 101, 569.

Laey, P. de, Hooft, C., Timmermans, J., and Snoeck, J. (1964). Biochemical aspects of Hartnup disease. Part I. Results of intravenous and oral tryptophan loading tests in a case of Hartnup disease. Ann. paediat. (Basel), 202, 145.

Milne, M. D., Crawford, M. A., Girão, C. B., and Loughridge, L. W. (1960). The metabolic disorder in Hartnup disease. Quart. f. Med., 29, 407.

Nemeth, A. M., and Nachmias, V. T. (1958). Changes in tryptophan peroxidase activity in developing liver. Science, 128, 1085.

Sharlit, H. (1933). A method for the quantitative estimation of indoxyl compounds in urine. $\mathcal{F}$. biol. Chem., 99, 537.

Srikantia, S. G., Venkatachalam, P. S., and Reddy, V. (1964). Clinical and biochemical features of a case of Hartnup disease. Brit. med. F., 186, 282.

Udenfriend, S., Titus, E., and Weissbach, H. (1955). The identification of 5-hydroxy-3-indoleacetic acid in normal urine and a method for its assay. $\mathcal{F}$. biol. Chem., 216, 499.

Visakorpi, J. K., Hjilt, L., Lahikainen, T., and Ohman, S. (1964). Hartnup disease in two siblings. Ann. Paediat. Fenn., 10, 42.

Weissbach, H., King, W., Sjoerdsma, A., and Udenfriend, S. (1959). Formation of indole-3-acetic acid and tryptamine in animals : a method for estimation of indole-3-acetic acid in tissues. $\mathcal{f}$. biol. Chem., 234, 81.

Weyers, H., and Bickel, H. (1958). Photodermatose mit Aminoacidurie, Indolaceturie und cerebralen Manifestationen (Hartnup-Syndrom). Klin. Wschr., 36, 893. 